\title{
Highest II: Climate Change at High Elevation Sites: Emerging Impacts
}

Davos, Switzerland 25-28 June 2001

5 years after the meeting Highest I: Climate Change at High Elevation Sites) 50 scientists from wide ranging interdisciplinary backgrounds met with the goal of synthesizing climate change impacts on ecosystems and humans at high altitudes. To open the meeting, Bruno Messerli underscored the importance of mountains as "water towers" supporting the needs of a sizable fraction of humanity.

One topic of discussion was quantifying and understanding the ongoing retreat of mountain glaciers worldwide, as exemplified by the case on Kilimanjaro shown on the cover on this newsletter. Debate about Kilimanjaro's glacial retreat centered around whether this indicated increasing local ambient temperatures and increased long wave radiation from the dark caldera surface (higher melt rates) or increased short wave radiation leading to enhanced sublimation, one possible explanation for the special perpendicular inward facing walls of these ice fields.

Further debate arose over the interpretation of $\delta^{180}$ records in ice cores. Ray Bradley and Mathias Vuille showed records from automatic weather stations placed at the exact sites where ice cores have been recovered, and argued that the snow which lasts through the year, and is thus incorporated in the ice cores, comes from a short seasonal timewindow. As a result $\delta 180$ would be expected to show a strong relationship to monthly variability in precipitation source and amount. Lonnie Thompson countered that these two years of data may provide some insight, but not on decadal and longer timescales. On these longer timescales the isotopic shifts in many of these cores are almost exactly the same as those from Greenland, arguing that the isotopes are indicating, in both locations, hemispheric scale temperature variability. Ulrich Schotterer showed that climatic interpretation of ice cores especially in arid regions as the Central Andes may be difficult due to the

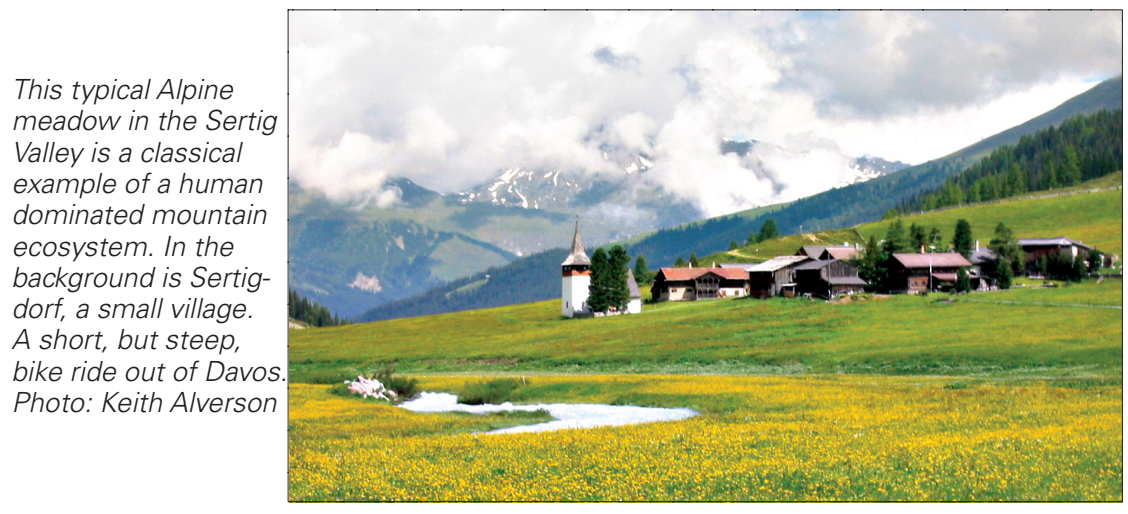

fact, that mass losses by sublimation both concentrates chemical species and reduces net accumulation dramatically.

Another topic of discussion was mountain ecosystem changes in recent years. Pavel Moiseev, one of three PAGES funded participants from developing countries, showed a stunning series of photographs from early in the century compared with the same locations during the last few years. Vegetation belts, and in particular treeline, has moved tens to hundreds of meters along the full north south extent of the Ural mountains. Discussion ensued about the reasons for these, and similar shifts in other parts of the world. Both pollen (Sonja Hausmann) and numerical models (Harald Bugman) clearly indicate that in heavily populated and intensely used mountain areas such as the Swiss Alps, tree line is largely determined by human land use practices, and has been for thousands of years. However in the Ural's and other remote ranges, these changes are not due to direct human influences. The question of $\mathrm{CO}_{2}$ fertilization vs climatic amelioration as possible drivers of these ecosystem changes was debated. Christian Koerner argued emphatically and convincingly that temperature, not photosynthetic efficiency, in general determined treeline elevations, with other processes such as moisture availability playing roles on regional scales. Interesting and important feedbacks also come into play, for example soil temperatures may warm allowing trees to expand upward or form closed canopies, but these closed stands will then shade the soil, leading to cooling of the soil and conditions no longer advantageous for the trees.

Finally, numerous presentations presented proxy records of Pacific decadal variability, from Pategonia to Alaska and attempted to quantify the magnitude and spatial expression of this climatic mode and its interaction with shorter timescale processes such as ENSO. Although the statistical nature of pacific decadal variability is clearly indicated in many proxy records, they do not always agree. Henry Diaz and Stefan Hastenrath provoked much debate as to whether this was a "real" phenomena, with a dynamical explanation, or simply a statistical querk. Alverson argued that cross correlations of the strong interdecadal signal in the accumulation record of the Mt. Logan ice core with both tropical SSTs and upper tropospheric pressure fields show a clear dynamical basis for the hemispheric expression of this teleconnection pattern in the meridional moisture transport associated with synoptic weather systems.

A special issue of Climatic Change that is being put together as a product from this meeting. The conference organizers and participants gratefully acknowledge the financial support of NOAA and the NSF in the United States, NCCR and SANW in Switzerland, PAGES, and the hosts in Davos. 